\title{
Cholesterol Ester and Triglyceride Metabolism in Intact Fibroblasts from Patients with Wolman's Disease and Cholesterol Ester Storage Disease
}

\author{
BARBARA K. BURTON, WANDA T. REMY, AND LEA RAYMAN \\ Department of Pediatrics, Wake Forest University Medical Center, Winston-Salem, North Carolina 27103
}

\begin{abstract}
Cholesterol ester and triglyceride metabolism was examined in intact fibroblast monolayers from normal individuals and patients with Wolman's disease and cholesterol ester storage disease. Cholesterol esters were introduced into cells by incubation in medium containing $\left[{ }^{3} \mathrm{H}\right]$ cholesteryl linoleate (CL) bound to human low density lipoprotein. Triglycerides were introduced by incubation with glycerol tri[1 $\left.-^{14} \mathrm{C}\right]$ oleate (triolein) bound to human very low-density lipoprotein. Both types of mutant cell lines accumulated the unhydrolyzed substrates to a greater extent than did normal cells with the greatest accumulation observed in Wolman's disease cells. Wolman's disease cells hydrolyzed CL at 10-22\% and triolein at 11-19\% the rate of normal cells; cholesterol ester storage disease cells hydrolyzed these substrates at $28-49$ and $30-47 \%$ the normal rate, respectively. In contrast, assays of acid lipase activity in cell lysates revealed less than $1 \%$ of control activity in both disorders. The data suggest that the mutant acid lipase present in Wolman's disease and cholesterol ester storage disease is more active in the intact cell than assays of cell lysates would indicate. In addition, the differences observed between the two disorders provide a biochemical explanation for the different phenotypes associated with the two disorders. (Pediatr Res 18:12421245, 1984)
\end{abstract}

\section{Abbreviations}

MEM, minimal essential medium LDL, low-density lipoprotein VLDL, very low-density lipoprotein CL, cholesteryl linoleate PBS, phosphate-buffered saline LPDS, lipoprotein-deficient serum

Wolman's disease and cholesterol ester storage disease are genetically distinct inborn errors of metabolism associated with a deficiency of lysosomal acid lipase activity $(6,15,19)$. Although both are characterized by accumulation of cholesterol esters and triglycerides in tissues, the clinical phenotypes are quite different. While Wolman's disease uniformly leads to death in early in-

Received March 14, 1984; accepted May 18, 1984.

Requests for reprints should be addressed to Dr. Barbara K. Burton, Department of Pediatrics, Wake Forest University Medical Center, 300 S. Hawthorne Road, Winston-Salem, NC 27103.

This research was supported in part by Summer Science Research Program for Medical Students Grant 8-83-62 from the March of Dimes Birth Defects Foundation. fancy, most patients with cholesterol ester storage disease have survived into adult life and many have been asymptomatic.

Deficient lysosomal acid lipase activity can be demonstrated in vitro in tissue or fibroblast lysates from patients with Wolman's disease and cholesterol ester storage disease using either cholesterol esters or triglycerides as substrates. In most studies, less than $5 \%$ of control activity has been observed $(4,6)$. Differences in residual activity that might account for the differing phenotypes in the two disorders have not been consistently demonstrated.

It has recently been demonstrated that enzyme activity as measured in fibroblast lysates in a number of disorders may not accurately reflect activity within the intact cell. Beaudet and Manschreck (1) and Kudoh et al. (14) observed significant differences in sphingomyelin hydrolysis between intact fibroblasts of patients with Niemann-Pick disease types A and B despite the fact that fibroblast lysates exhibit a similar severe deficiency of sphingomyelinase activity in the two forms of the disorder. In addition, these investigators were able to correlate the clinical phenotypes with the levels of residual activity observed in the intact cell. Similarly, studies of cerebroside sulfate hydrolysis in intact fibroblasts have been useful in differentiating between metachromatic leukodystrophy and the benign pseudo arylsulfatase A deficiency, both of which are associated with very low levels of arylsulfatase $A$ and cerebroside sulfatase activity in cell lysates $(9,13)$.

We report here the results of our investigation of the metabolism of cholesterol esters and triglyceride by intact cell monolayers from patients with Wolman's disease and cholesterol ester storage disease. Significant differences in residual acid lipase activity are observed which may explain the phenotypic differences between the two disorders.

\section{MATERIALS AND METHODS}

Materials. Cholesteryl $\left[1-{ }^{14} \mathrm{C}\right]$ oleate and glycerol tr $\left[1-{ }^{14} \mathrm{C}\right]$ oleate (triolein) were purchased from Amersham (Arlington Heights, IL) $\left[{ }^{3} \mathrm{H}\right]$ Cholesteryl linoleate was from New England Nuclear (Boston, MA). Unlabeled cholesteryl oleate and triolein and bovine serum albumin were from Sigma (St. Louis, MO). Eagle's MEM and fetal calf serum were obtained from Gibco (Grand Island, NY) Silica gel $\mathrm{H}$ plates $(500 \mu \mathrm{m})$ used for thin layer chromatography were from Analtech (Newark, DE).

Tissue culture. Fibroblast cultures were established from skin biopsies obtained from normal controls who gave informed consent. Cell lines from three patients with Wolman's disease (GM 1606, GM 2109, and GM 2211) and one patient with cholesterol ester storage disease (GM 863) were obtained from the Human Genetic Mutant Cell Repository, Camden, NJ. An additional cell line from a patient with cholesterol ester storage disease (K. W.) was obtained from Dr. A. L. Beaudet and a third 
(P. W.) from Dr. P. M. Coates. Cells were cultivated in MEM supplemented with $15 \%$ fetal calf serum and a commercial antibiotic-antimycotic solution in an atmosphere of $5 \% \mathrm{CO}_{2}$. For assays of enzyme activity in cell lysates, the medium was decanted at confluency and the cells were washed twice with normal saline and then harvested using $0.25 \%$ trypsin in normal saline. The cell pellets were washed twice in normal saline and resuspended in distilled water. Lysates were prepared by three 10 -s bursts of sonication using a Sonic 300 dismembranator with microtip and were subsequently centrifuged for $10 \mathrm{~min}$ at $1000 \times g$.

Assays using cell lysates. Acid lipase activity was measured with the substrates cholesteryl $\left[1-{ }^{14} \mathrm{C}\right]$ oleate and glycerol tri[ 1 ${ }^{14}$ C]oleate (triolein) as previously described (5). Protein was assayed by the Folin method using bovine serum albumin as a standard (16). Assays of acid lipase activity using $\left[{ }^{3} \mathrm{H}\right] \mathrm{CL}-\mathrm{LDL}$ as substrate contained the following in a final volume of $100 \mu \mathrm{l}$ : $0.1 \mathrm{M}$ acetate buffer, pH 4.0, $5 \mathrm{mM}$ 2-mercaptoethanol; $1 \mathrm{mM}$ EDTA; $0.5 \mathrm{mg} / \mathrm{ml}$ bovine serum albumin; $100 \mu \mathrm{g}$ fibroblast protein, and [ $\left.{ }^{3} \mathrm{H}\right] \mathrm{CL}-\mathrm{LDL}(14.2 \mu \mathrm{g}$ LDL protein, $28,048 \mathrm{cpm} /$ nmol of total cholesteryl linoleate). The reaction was incubated for $1 \mathrm{~h}$ at $37^{\circ} \mathrm{C}$ and then stopped by the addition of $400 \mu \mathrm{l}$ of chilled distilled water. The $\left[{ }^{3} \mathrm{H}\right]$ cholesterol liberated was isolated and measured as described below for cell monolayers. Enzyme activity was expressed as pmol $\left[{ }^{3} \mathrm{H}\right]$ cholesterol liberated/mg lysate protein, after subtracting blank values determined using boiled lysates.

Preparation of $\left[{ }^{3} H\right]$ cholesteryl linoleate-LDL and glycerol tri/ $1-{ }^{14}$ Cloleate-VLDL. Human LDL (12), VLDL (12), and LPDS (20) were prepared by differential ultracentrifugation of plasma obtained from normal volunteers. $\left[{ }^{3} \mathrm{H}\right]$ Cholesteryl linoleate was bound to LDL using methods previously described (21). The $\left[{ }^{3} \mathrm{H}\right] \mathrm{CL}-\mathrm{LDL}$ was subsequently purified by agarose column chromatography (18). The specific activity of various preparations ranged from $10,000-30,000 \mathrm{cpm} / \mathrm{nmol}$ total cholesteryl linoleate. VLDL was labeled with radioactive triolein using the method of Fielding (8) except that fasting human plasma was used instead of rat plasma.

Metabolism of ${ }^{\beta} H J C L-L D L$ by intact cell monolayers. At confluency, the culture medium was decanted from $75-\mathrm{cm}^{2}$ flasks of cells and the cells were washed three times with sterile PBS. The medium was then replaced with $10 \mathrm{ml}$ of fresh MEM containing 5\% human LPDS and no fetal calf serum. The cells were incubated for $24 \mathrm{~h}$ at $37^{\circ} \mathrm{C}$ and then washed once with sterile PBS. Ten $\mathrm{ml}$ of fresh MEM containing 5\% human LPDS and $\left[{ }^{3} \mathrm{H}\right] \mathrm{CL}-\mathrm{LDL}(10 \mu \mathrm{g}$ LDL protein $/ \mathrm{ml} ; 10,000 \mathrm{cpm} / \mathrm{ml})$ were added to each flask and the cells were again incubated at $37^{\circ} \mathrm{C}$. The concentration of LDL in the medium was arbitrarily selected to provide adequate intracellular radioactivity and was probably not saturating with respect to receptor-mediated uptake (10). At varying intervals $(0,1,3,6,12,24$, and $48 \mathrm{~h})$, flasks were placed on ice, the medium was removed, and the cells were washed three times with cold PBS. The cells were harvested using $0.25 \%$ trypsin and washed twice with normal saline. Cell pellets were resuspended in distilled water, sonicates were prepared, and aliquots were removed for determinations of protein and total intracellular radioactivity. Lipids were extracted using the Bligh-
Dyer method (3) and separated by thin layer chromatography using silica gel $\mathrm{H}$ plates in a solution of hexane:ethyl ether:acetic acid $(70: 30: 1)$. The standard spots were visualized by iodine vapor and the plates were scored according to the standards. Each area was scraped into a scintillation vial to which $5 \mathrm{ml}$ of scintillation fluid (Instagel, Packard) was added. Radioactivity was measured in a Packard Tri-Carb liquid scintillation spectrometer. Duplicate flasks of each cell line were harvested at each time interval. Blanks consisted of flasks incubated and treated in a manner identical to that with experimental flasks except that labeled CL-LDL was replaced in the medium by unlabeled LDL.

Metabolism of glycerol tri ${ }^{14}$ CJoleate-VLDL by intact cell monolayers. Cells were preincubated for $48 \mathrm{~h}$ with medium containing LPDS as described for experiments using CL-LDL. Ten $\mathrm{ml}$ of MEM containing 5\% human LPDS and labeled VLDL $(0.5 \mu \mathrm{g}$ VLDL protein $/ \mathrm{ml} ; 10,000 \mathrm{cpm} / \mathrm{ml})$ were added to each flask. The concentration of VLDL in the medium was arbitrarily selected to provide adequate intracellular radioactivity. No experiments were performed to determine the concentration of VLDL required to saturate the receptor-mediated uptake process. Cells were subsequently incubated and harvested and the lipids were extracted and separated in the same manner described for experiments using CL-LDL.

\section{RESULTS}

Assays of acid lipase activity in cell lysates reveal less than 3\% of control activity in Wolman's disease and cholesterol ester storage disease when either cholesteryl oleate or triolein is utilized as substrate (Table 1). Although cholesterol ester storage disease cells tend to exhibit slightly higher levels of residual activity, overlap is observed. When $\left[{ }^{3} \mathrm{H}\right] \mathrm{CL}-\mathrm{LDL}$ is utilized as substrate, somewhat higher levels of residual activity are observed and a difference is noted between the two cell types $(0-5 \%$ control activity in Wolman's disease cells; $7-10 \%$ in cholesterol ester storage disease cells).

Experiments with intact cell monolayers indicate that $\left[{ }^{3} \mathrm{H}\right]$ cholesteryl linoleate bound to LDL readily enters mutant and normal cells and is subsequently hydrolyzed rapidly to yield free $\left[{ }^{3} \mathrm{H}\right]$ cholesterol in normal cells. Significantly more hydrolysis is observed in mutant cells than would be anticipated on the basis of assay results in cell lysates. A representative experiment comparing the rate of substrate accumulation and hydrolysis in normal, Wolman's disease, and cholesterol ester storage disease cells is seen in Figure 1. Figure $1 A$ depicts the accumulation over time of radioactivity in the cholesterol ester fraction of the three cell types. Both mutant cell lines accumulate cholesterol esters to a greater extent than do controls with the greatest accumulation observed in Wolman's disease cells. Figure $1 B$ depicts the appearance over time of free $\left[{ }^{3} \mathrm{H}\right]$ cholesterol in the three cell types as a result of hydrolysis of the cholesterol ester by the lysosomal acid lipase. Again it is apparent that both cell lines are deficient in hydrolytic activity although the Wolman's disease cells are significantly more deficient than the cholesterol ester storage disease cells. In this particular experiment, Wolman's disease and cholesterol ester storage disease cells exhibit 19 and $32 \%$ of control hydrolytic activity, respectively (as calculated by

Table 1. Acid lipase activity in fibroblast lysates

\begin{tabular}{lccc}
\hline & \multicolumn{1}{c}{ Substrate } & \\
\cline { 2 - 4 } \multicolumn{1}{c}{ Cell type } & $\begin{array}{c}\text { Triolein } \\
\text { (nmol substrate hydrolyzed/ } \\
\text { h/mg protein) }\end{array}$ & $\begin{array}{c}\text { Cholesteryl oleate } \\
\text { (nmol substrate hydrolyzed/ } \\
\text { h/mg protein) }\end{array}$ & $\begin{array}{c}\text { Cholesteryl linoleate-LDL } \\
\text { (pmol [ } \begin{array}{c}{ }^{3} \mathrm{H} \text { ]cholesterol formed/ } \\
\mathrm{h} / \mathrm{mg} \text { protein) }\end{array}\end{array}$ \\
\hline Controls* $(n=8)$ & $16.2 \pm 2.7$ & $5.0 \pm 1.3$ & $345.0 \pm 66.0$ \\
Wolman's disease $(n=3)$ & $0.03,0.09,0.16$ & $0.01,0.01,0.02$ & $0,9,16$ \\
Cholesterol ester storage dis- & $0.12,0.17,0.34$ & $0.02,0.05,0.12$ & $24,32,36$
\end{tabular}

ease $(n=3)$

* Control values represent the mean \pm S.D. 


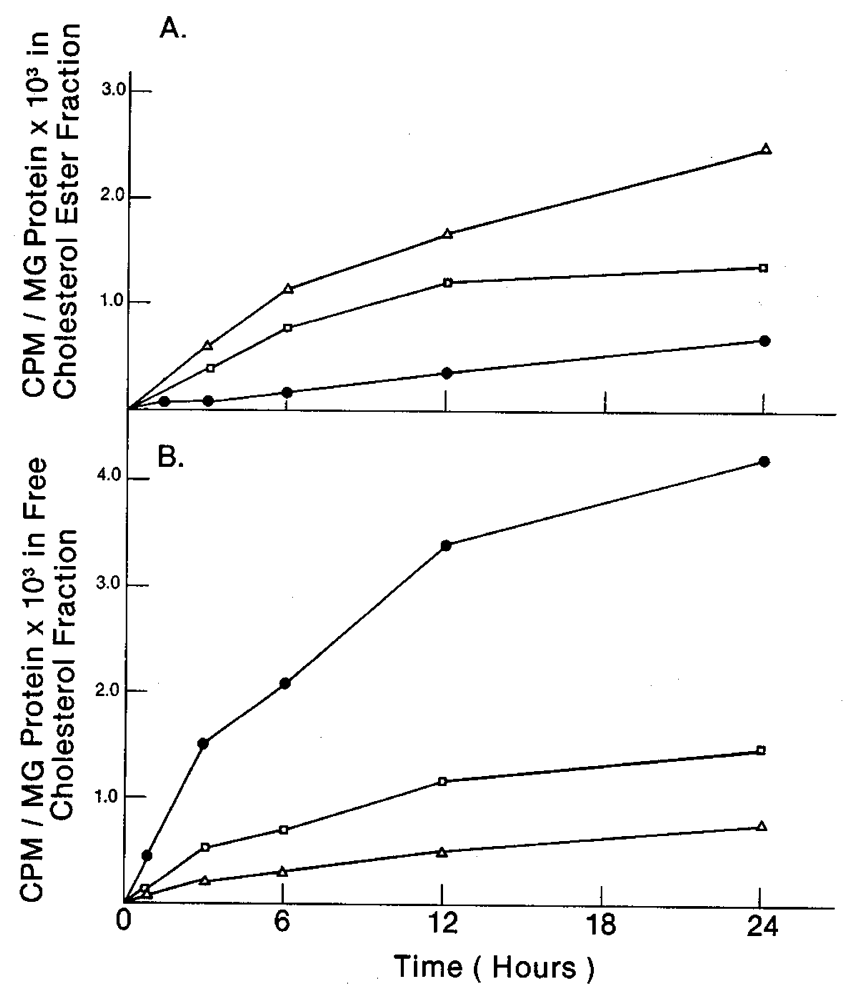

Fig. 1. Cholesterol ester accumulation and hydrolysis by intact fibroblasts from a normal individual (๑), a patient with Wolman's disease $(\mathrm{GM} 1606)(\triangle)$, and a patient with cholesterol ester storage disease (GM

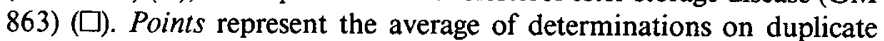
flasks.

the ratio of $\mathrm{cpm}$ in the free cholesterol fraction of mutant and normal cells at $3 \mathrm{~h}$ ).

Similar experiments were conducted using six control cell lines and three cell lines each from Wolman's disease and cholesterol ester storage disease patients. One or two cell lines of each type were used in a typical experiment and each cell line was studied at least twice. Although measured radioactivity varied somewhat from experiment to experiment, the relationship between the three types of cell lines with regard to cholesterol ester accumulation and hydrolysis was always preserved. This is illustrated in Table 2 in which the results of the various experiments are tabulated. Wolman disease cell lines hydrolyzed the $\left[{ }^{3} \mathrm{H}\right]$ cholesteryl linoleate-LDL at $10-22 \%$ of the control rate while cholesterol ester storage disease cells consistently exhibited greater hydrolytic activity ( $28-49 \%$ of control).

Eighty-three to $88 \%$ of the total intracellular radioactivity measured prior to extraction of lipids was recovered in the cholesterol ester and free cholesterol fractions combined. No more than $5 \%$ of the radioactivity detected in the intracellular free cholesterol fraction was detected in the free cholesterol fraction of the culture medium of any cell line at 0,12 , and 24 h.

Experiments performed using labeled VLDL indicate that triglyceride was readily taken up by mutant and normal cells in a uniform fashion, presumably as a result of binding of the VLDL to LDL receptors on the cell surface. In contrast, previous experiments attempted in our laboratory using free radiolabeled triolein dispersed in culture medium had resulted in very erratic uptake by cells. Once inside the cell, the labeled VLDL-bound triolein was rapidly hydrolyzed to yield glycerol mono $\left[1-{ }^{14} \mathrm{C}\right]$ oleate and glycerol di $\left[1-{ }^{14} \mathrm{C}\right]$ oleate as well as free oleic acid. Significant radioactivity, increasing as a function of time, was also detected in the phospholipid fraction of cell extracts. Previous investigators have demonstrated that the lysosomal acid lipase has little or no monoglyceride lipase activity (17) so the activity of this enzyme in the intact cell was monitored by measuring the appearance of radioactivity in the monolein and diolein fractions.

The results of a representative experiment are depicted in Figure 2. Figure $2 A$ illustrates the accumulation of the labeled triglyceride in cells over time, clearly greater in mutant then in normal cells and most striking in cells of the patient with Wolman's disease. Figure $2 B$ illustrates the appearance of radioactivity in the mono- and diglyceride fractions and demonstrates differences between mutant and normal cells in their ability to hydrolyze triglycerides. Although deficient as compared to nor-

Table 2. Hydrolysis of exogenous lipids by intact monolayers of acid-lipase-deficient fibroblasts*

\begin{tabular}{lcc}
\hline & \multicolumn{2}{c}{ Activity (\% of control) } \\
\cline { 2 - 3 } Cell line & Cholesteryl linoleate-LDL $\dagger$ & Triolein-VLDL $\ddagger$ \\
\hline Wolman's disease & & \\
GM 2109 & $11.1-18.5$ & $12.0-17.0$ \\
GM 1606 & $14.7-22.0$ & $13.2-19.0$ \\
GM 2211 & $10.1-19.5$ & $11.6-15.8$ \\
Cholesterol ester & & \\
storage dis- & & \\
ease & $31.6-49.8$ & $36.4-47.5$ \\
GM 863 & $33.0-42.5$ & $34.0-39.7$ \\
K. W. & $28.3-39.8$ & $31.2-42.5$ \\
P. W. & &
\end{tabular}

* After $3 \mathrm{~h}$ of incubation with cholesteryl linoleate-LDL, control cells contained $1300-3250 \mathrm{cpm} / \mathrm{mg}$ protein in the free cholesterol fraction; after $3 \mathrm{~h}$ of incubation with triolein-VLDL, they contained $910-2500$ $\mathrm{cpm} / \mathrm{mg}$ protein in the monolein and diolein fractions combined.

$\dagger$ Hydrolysis measured by rate of appearance of $\left[{ }^{3} \mathrm{H}\right]$ cholesterol.

$\$$ Hydrolysis measured by rate of appearance of glycerol mono $\left[1-{ }^{14} \mathrm{C}\right]$ oleate and glycerol di $\left[1-{ }^{14} \mathrm{C}\right]$ oleate.

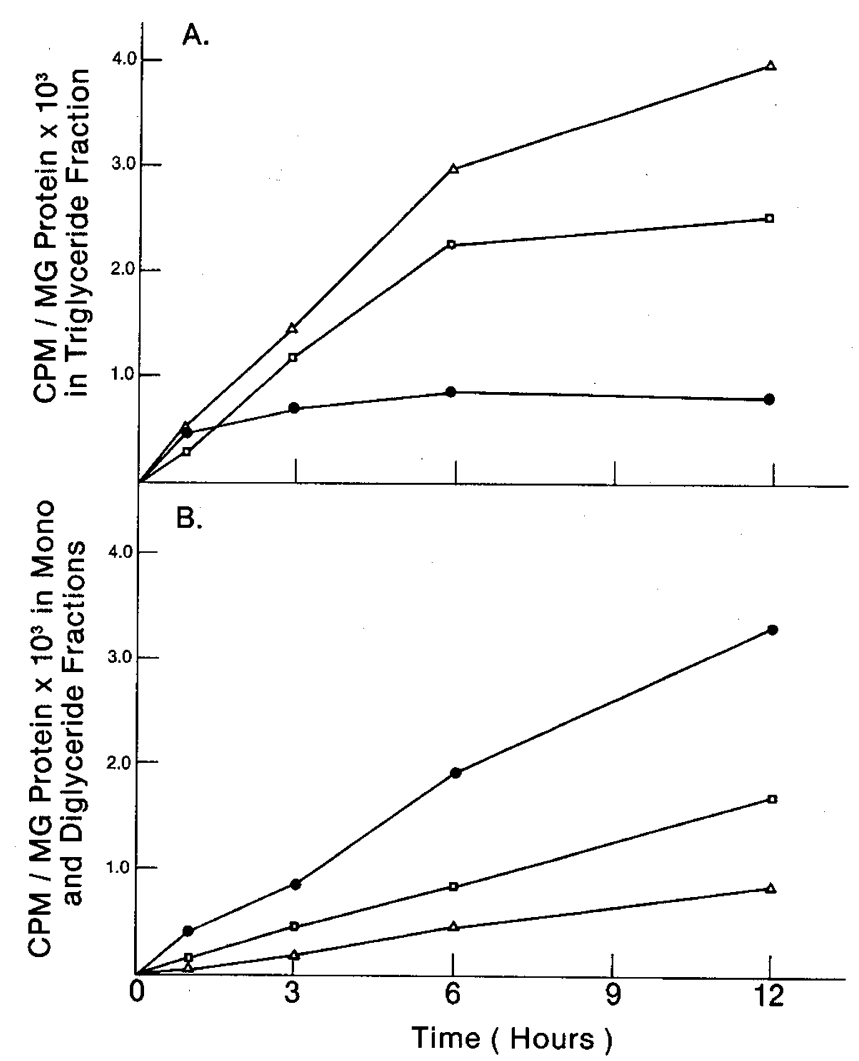

Fig. 2. Triglyceride accumulation and hydrolysis by intact fibroblasts from a normal individual (๑), a patient with Wolman's disease (GM 2109) $\triangle$ ), and a patient with cholesterol ester storage disease (GM 863) ( $\square$ ). Points represent the average of determinations on duplicate flasks. 
mal cells, cholesterol ester storage disease cells consistently exhibited greater hydrolytic activity than did Wolman's disease cells. A summary of the experience with all cell lines studied is seen in Table 2. Cholesterol ester storage disease cells exhibited $30-47 \%$ control hydrolytic activity toward the triolein-VLDL while Wolman's disease cells exhibited $11-19 \%$ control activity. These levels of residual activity are similar to those observed in the experiments utilizing CL-LDL.

The ratio of radioactivity in the monolein and diolein fractions in the two types of mutant cells was similar and differed slightly from that observed in normal cells at each time point studied up to $12 \mathrm{~h}$. In normal cells, the average percentage of radioactivity in the combined fractions accounted for by monolein at 1, 3, 6 , 12 , and $24 \mathrm{~h}$ was $82,89,90$, and $94 \%$, respectively. In Wolman's disease cells, $71,74,81,87$, and $92 \%$ of the counts were in the monolein fraction; in cholesterol ester storage disease cells, 72 , $78,82,89$, and $94 \%$ of the counts were in this fraction. Seventynine to $84 \%$ of total intracellular radioactivity was recovered following thin layer chromatography.

\section{DISCUSSION}

Metabolism of cholesterol esters and triglycerides has not previously been extensively evaluated in intact cells from acid lipase-deficient patients. Goldstein et al. (10) studied $\left[{ }^{3} \mathrm{H}\right]$ cholesteryl linoleate-LDL metabolism in a single cell line from a patient with cholesterol ester storage disease and demonstrated that these cells hydrolyzed the cholesterol ester to produce free $\left[{ }^{3} \mathrm{H}\right]$ cholesterol at about one-third the rate of normal cells. This finding correlates well with the results of the present study. In a subsequent publication, Goldstein and Brown (11) reported 5\% the control rate of hydrolysis of CL-LDL in a cholesterol ester storage disease cell line and less than $2 \%$ in a Wolman's disease cell line although specific data and details of the experimental conditions were not provided. Our data indicate that intact acid lipasedeficient fibroblasts are capable of hydrolyzing cholesterol esters and triglycerides introduced into cells through binding to lipoproteins but at a lower rate than normal cells. Significantly greater residual activity is observed than would be anticipated on the basis of in vitro assays of acid lipase activity in cell lysates. Wolman's disease cells exhibit 10-20\% of control hydrolytic activity while cholesterol ester storage disease cells exhibit 30$45 \%$ of control activity. There are several possible explanations for this observation. The most likely explanation is that the mutant enzyme present in each of the two disorders may be significantly more active in the intact cell than in cell lysates which provide an artificial environment for enzymatic activity that clearly does not parallel conditions occurring in vivo. An alternate explanation is that there may be a nonlysosomal pathway for cholesterol ester and triglyceride metabolism in fibroblasts, unaffected in acid lipase-deficient cells, which accounts for the hydrolysis observed in Wolman's disease cells and some of the hydrolysis observed in cholesterol ester storage disease cells. If this is the case, then it would be necessary to postulate that some of the labeled lipid entering the cell did not localize within the lysosome. There is evidence for the presence of a neutral lipase in cultivated fibroblasts that is capable of hydrolyzing triolein and cholesterol oleate although published data suggest that the activity of this enzyme is also deficient in cell lysates of patients with Wolman's disease and cholesterol ester storage disease (17). Goldstein et al. (10) have provided some evidence against this explanation as well by demonstrating under experimental conditions similar to ours that the hydrolysis of CL-LDL by their cell line from a patient with cholesterol ester storage disease was completely inhibited by chloroquine, suggesting that it was entirely lysosomal in origin. In view of these findings, we feel it is likely that the activity measured in the present experiments does reflect activity of the mutant acid lipase.

As compared to normal cells, both types of mutant cells exhibit a reduction in hydrolytic activity that is similar in degree toward the two types of lipid substrates. Clear differences are observed between the two disorders, however, with cholesterol ester storage disease cells consistently exhibiting greater residual enzymatic activity and less striking accumulation of the unhydrolyzed cholesteryl lineoleate or triolein. These differences parallel the clear differences in clinical severity between the two disorders and would appear to provide a biochemical explanation for the differing phentotypes.

Our experiments indicate that triglycerides can be successfully introduced into cultivated fibroblasts through binding to VLDL and support the conclusion that VLDL is able to bind to LDL receptors on the cell surface. The utilization of this technique may facilitate the further investigation of triglyceride metabolism in intact cultivated cells.

Acknowledgments. The authors gratefully acknowledge the technical advice provided by Ms. Molly Leight and Ms. Mary Thomas.

\section{REFERENCES}

1. Beaudet AL, Manschreck AA 1982 Metabolism of sphingomyelin by intact cultured fibroblasts: differentiation of Niemann-Pick disease types A and B. Biochem Biophys Res Commun 105:14

2. Deleted in proof

3. Bligh EG, Dyer WJ 1959 A rapid method of total lipid extraction and purification. Can J Biochem Physiol 37:911

4. Burton BK. Emery D, Mueller HW 1980 Lysosomal acid lipase in cultured fibroblasts: characterization of enzyme activity in normal and enzymatically deficient cell lines. Clin Chim Acta 101:25

5. Burton BK, Mueller HW 1980 Purification and properties of human placental acid lipase. Biochim Biophys Acta 618:449

6. Cortner JA, Coates PM, Swoboda E, Schnatz JD 1976 Genetic variation of lysosomal acid lipase. Pediatr Res 10:927

7. Deleted in proof

8. Fielding CJ 1979 Validation of a procedure for exogenous isotopic labeling of lipoprotein triglyceride with radioactive triolein. Biochim Biophys Acta 573:255

9. Fluharty AL, Stevens RL, Kihara H 1978 Cerebroside sulfate hydrolysis by fibroblasts from a metachromatic leukodystrophy patient with deficient arylsulfatase A. J Pediatr 92:782

10. Goldstein JL, Dana SE, Faust JR, Beaudet AL, Brown MS 1975 Role of lysosomal acid lipase in the metabolism of plasma low density lipoprotein. J Biol Chem 250:8487

11. Goldstein JL, Brown MS 1977 The low-density lipoprotein pathway and its relation to atherosclerosis. Annu Rev Biochem 46:897

12. Havel RJ, Eder HA, Bragdon JH 1955 The distribution and chemical composition of ultracentrifugally separated lipoproteins in human serum. J Clin Invest 34:1345

13. Kihara H, Ho C, Fluharty AL, Tsay KK, Hartlage PL 1980 Prenatal diagnosis of metachromatic leukodystrophy in a family with pseudo arylsulfatase A deficiency by the cerebroside sulfate loading test. Pediatr Res 14:224

14. Kudoh T, Velkoff MA, Wenger DA Uptake and metabolism of radioactively labeled sphingomyelin in cultured skin fibroblasts from controls and patients with Niemann-Pick disease and other lysosomal storage diseases. Biochim Biophys Acta 754:82

15. Kyriakides EC, Filippone M, Paul B, Gratten W, Balint JA 1970 Lipid studies in Wolman's disease. Pediatrics 46:431

16. Lowry OH, Rosebrough NJ, Farr AL, Randall RJ 1951 Protein measurement with the Folin phenol reagent. J Biol Chem 193:265

17. Messieh S, Clarke JTR, Cook HW, Spence MW 1983 Abnormal neutral lipase activity in acid-lipase-deficient cultured human fibroblasts. Pediatr Res $17: 770$

18. Rudel LL, Lee JA, Morris MD, Felts JM 1974 Characterization of plasma lipoproteins separated and purified by agarose-column chromatography. Biochem J 139:89

19. Sloan HR, Fredrickson DS 1972 Enzyme deficiency in cholesterol ester storage disease. J Clin Invest 51:1923

20. St. Clair RW, Smith BP, Wood LL 1977 Stimulation of cholesterol esterification in rhesus monkey arterial smooth muscle cells. Circ Res 40:166

21. St. Clair RW, Greenspan P, Leight M 1983 Enhanced cholesterol delivery to cells in culture by low density lipoproteins from hypercholesterolemic monkeys. Arteriosclerosis 3:77 